First Peoples Child \& Family Review

An Interdisciplinary Journal Honouring the Voices, Perspectives, and Knowledges of First Peoples through Research, Critical Analyses, Stories, Standpoints and Media Reviews

\title{
Conversation Method in Indigenous Research
}

\section{Margaret Kovach}

Volume 5, Number 1, 2010

URI: https://id.erudit.org/iderudit/1069060ar

DOI: https://doi.org/10.7202/1069060ar

See table of contents

Publisher(s)

First Nations Child and Family Caring Society of Canada

ISSN

1708-489X (print)

2293-6610 (digital)

Explore this journal

Cite this article

Kovach, M. (2010). Conversation Method in Indigenous Research. First Peoples Child \& Family Review, 5(1), 40-48. https://doi.org/10.7202/1069060ar

\section{Article abstract}

In reflecting upon two qualitative research projects incorporating an Indigenous methodology, this article focuses on the use of the conversational method as a means for gathering knowledge through story. The article first provides a theoretical discussion which illustrates that for the conversational method to be identified as an Indigenous research method it must flow from an Indigenous paradigm. The article then moves to an exploration of the conversational method in action and offers reflections on the significance of researcher-in-relation and the inter- relationship between this method, ethics and care.
This document is protected by copyright law. Use of the services of Erudit (including reproduction) is subject to its terms and conditions, which can be viewed online.

https://apropos.erudit.org/en/users/policy-on-use/ 


\title{
INivest Peopples Choild \& warnothy Review
}

An Interdisciplinary Journal Honoring the Voices, Perspectives and Knowledges of First Peoples through Research, Critical Analyses, Stories, Standpoints and Media Reviews

Volume 5, Number 1, 2010, p. 40-48

\section{Conversational Method in Indigenous Research}

\author{
Margaret Kovach ${ }^{\mathrm{a}}$
}

a PhD, Assistant Professor, Educational Foundations, University of Sasktachewan, Saskatoon, Saskatchewan.

\section{Introduction}

Indigenous knowledges comprise a specific way of knowing based upon oral tradition of sharing knowledge. It is akin to what different Indigenous researchers, the world over, identify as storytelling, yarning, talk story, re-storying, re-membering (Thomas, 2005; Bishop, 1999; Absolon \& Willett, 2004). In this article I refer to this same approach as the conversational method. The conversational method is a means of gathering knowledge found within Indigenous research. The conversational method is of significance to Indigenous methodologies because it is a method of gathering knowledge based on oral story telling tradition congruent with an Indigenous paradigm. It involves a dialogic participation that holds a deep purpose of sharing story as a means to assist others. It is relational at its core. In exploring the conversational method, this article first sets the context through a theoretical discussion of Indigenous methodologies as a paradigmatic approach. It then proceeds to a concerted focus on conversation as method. To highlight the practical application of the conversational method, I offer a commentary on two research projects I have carried out using this method. The article concludes with a reflection on the implications arising from the inter-relationship between method, ethics, and care when using the conversational method.

Why a focus on method? In reflecting upon research methods generally Wilson (2001) points out that there are

Questions or correspondence concerning this article may be addressed to:

m.kovach@usask.ca

\begin{abstract}
In reflecting upon two qualitative research projects incorporating an Indigenous methodology, this article focuses on the use of the conversational method as a means for gathering knowledge through story. The article first provides a theoretical discussion which illustrates that for the conversational method to be identified as an Indigenous research method it must flow from an Indigenous paradigm. The article then moves to an exploration of the conversational method in action and offers reflections on the significance of researcher-in-relation and the inter-relationship between this method, ethics and care.
\end{abstract}

methods that are "useful from an Indigenous perspective" and some which "are really built on the dominant paradigms, and they are inseparable from them" (p. 177). In making this claim, Wilson's argument supports the notion that Indigenous methodologies are a paradigmatic approach based upon an Indigenous philosophical positioning or epistemology. Thus it is not the method, per se, that is the determining characteristic of Indigenous methodologies, but rather the interplay (the relationship) between the method and paradigm and the extent to which the method, itself, is congruent with an Indigenous worldview. From this perspective, one could argue that the focal discussion of Indigenous methodologies ought to be a deep concentration of worldview or paradigm. As an Indigenous academic situated within a western university setting, the political and pedagogical significance of the point I cannot argue. Yet, locating my professional identity as that of a research instructor in first Social Work then Education, I am often engaged with matters of method. In further reflecting upon the experiential aspect of Indigenous approaches to learning and knowing, I recognize that our doing is intricately related with our knowing. We need only to look to the importance of protocol within Indigenous communities to recognize that how activities (i.e. methods) are carried out matter. Protocols are a means to ensure that activities are carried 
out in a manner that reflects community teachings and are done in a good way. The same principle ought to apply to research.

As Indigenous methodologies (and its methods) are relatively recent to western research methodological discourse, presenting ideas herein is meant to contribute to a critically reflective participatory dialogue of what it means to bring old knowledges as Indigenous into places that are new to them as academic research. It is a critically reflective 'think piece' inspired by reflections upon my experience with research involving Indigenous research frameworks.

Manu Aluli Meyer (2001) proposes there is an abundance of "10-dollar words" (p. 101) within academia. Given this particular, oft perilous, situation defining terms can never hurt. This article includes reference to four specific terms: paradigm, ontology, epistemology, and methodology. The term paradigm as used within a research context includes a philosophical belief system or worldview and how that belief system or worldview influences a particular set of methods. A paradigm is both theory and practice. Ontology is a theory or set of beliefs about the world (Strega, 2005; Mertens, 2005). The term epistemology is defined as knowledge nested within the social relations of knowledge production. It has been a term used by Indigenous researchers to express Indigenous worldview or philosophy (Ermine, 1995; Meyer, 2001; Wilson, 2008). It most closely approximates the term of "self-in-relation" as put forth by Graveline (2000, p. 361). Lincoln and Guba (as cited in Mertens, 2005) describe methodology as the process of gathering knowledge by stating that "the methodological question asks, "How can the knower go about obtaining the desired knowledge and understandings?”” (p. 8).

\section{Indigenous Methodologies as Paradigmatic Approach to Research}

Because Indigenous methodologies are relatively emergent within western qualitative research (Absolon \& Willett,2004; Kovach, 2005) it is useful to explain what exactly is meant by the claim that Indigenous methodologies are a paradigmatic approach. Within a paradigmatic approach to research, the paradigm influences the choice of methods (i.e. why a particular method is chosen), how those methods are employed (i.e. how data is gathered), and how the data will analyzed and interpreted. As Neuman (2006) reminds, a paradigm is a basic orientation to theory and thus impacts method. Within this approach, significant attention is paid to assumptions about knowledge. This is differentiated from a more pragmatic approach (or applied research) which is "not committed to any one system of philosophy and reality” (Creswell, 2003, p.12). In a paradigmatic approach to research, be it Indigenous or otherwise, methods ought to be congruent with the philosophical orientation identified in the research framework to show internal methodological consistency. If a researcher chooses to use an Indigenous methodological framework, the methods chosen should make sense from an Indigenous knowledges perspective.

In clarifying a paradigm itself, discussion of both form and substance are important because they influence each other. In research design, the academic community has adopted an organizational language that gives form/structure to aid in defining knowledge assumptions. Such definitions are commonly expressed through the language of ontology, epistemology, and methodology (Creswell, 2003; Neuman, 2006). The expectation is that a researcher will define the ontology, epistemology, and methodology according to his or her perspective and then clearly articulate that particular positioning. (Of course, what appears as a straightforward, definitional task gets deep and messy fast.)

The organizational form becomes akin to a series of boxes, to be filled, with labels marked ontology, epistemology, and methodology. Lincoln and Guba expand upon traditional definitions of research paradigms and suggest that a paradigm must include seven considerations: ethics, accommodation, action, control, truth, validity, and voice (as cited in Denzin \& Lincoln, 2003). Boxes within boxes, these categorical definitions, further assist the researcher in clarifying, and hopefully making visible, the belief system guiding the research. Metaphorically, I see a paradigm as similar to a nest holding chicks/hatchlings within it. For example, in a research project which incorporates an Indigenous methodology, the paradigm (nest) would be Indigenous knowledges with specific contextual knowledge assumptions emerging from a particular tribal knowledge base. Thompson's doctoral research is a case in point. She identifies her research as incorporating an Indigenous methodology, as shared among many Indigenous peoples, but based upon the contextual specifics of her Tahltan tradition (Thompson, 2008).

In their writing, Indigenous researchers have, to a certain extent, engaged in conversation on paradigm as form. In articulating the theoretical assumptions of the theory of Tsawalk , which underlies oosumich a Nuu-chah-nulth research method, Atleo differentiates knowledge assumptions from knowledge organizing systems. He points out that the theory of Tsawalk does not necessarily challenge the organizational form (or language) of paradigm and methodology itself but rather that the theory of Tsawalk holds knowledge assumptions alternative to that found within existing physical sciences (Atleo, 2004). In this sense he is referencing the substance of a paradigm. In her research on Native health, Stewart (2009) articulates the relational assumption underlying research methodology. 
She states that from an Indigenous research perspective the relational is viewed as an aspect of methodology whereas within western constructs the relational is viewed as bias, and thus outside methodology. As with Atleo, Stewart is not contesting the paradigmatic structure per se and is focusing specifically on paradigmatic substance. However, Stewart can be interpreted as stating that within Indigenous methodologies the categorical units (of ontology, epistemology, methodology) are not simply more elastic, but shapeshift to accommodate a worldview outside of western tradition. While certain western research paradigms frown upon the relational because of its potential to bias research, Indigenous methodologies embrace relational assumptions as central to their core epistemologies.

One could argue that Lincoln and Gubás seven considerations of a research paradigm (i.e. ethics, accommodation, action, control, truth, validity, and voice) cited above can accommodate the relational assumption of Indigenous research. However, the relational assumption of Indigenous methodologies seeks equal focus to that which connects the parts as much as the parts in and of themselves (whether it be two, four or eight considerations). It is the oft ephemeral, non-discrete moments that form a lasting inter-relationship of the hatchlings/ chicks in the nest that offer knowledge in understanding the chicks themselves, the chicks as family/community, the nest itself, and the world outside of the nest. For some, this is experienced as the spiritual aspect of Indigenous knowledges. Indigenous scholars (Little Bear 2000; Deloria 2004; Castellano, 2000) have effectively utilized this especially western-influenced knowledge organizing system to bring forward Indigenous worldviews. As a result Indigenous knowledges have arrived in mainstream post-secondary research contexts. The nuances and complexities of an Indigenous paradigm may not be fully understood (or viewed as legitimate) by all members of the academy, but few would openly contest, at least in public spaces, that an Indigenous paradigm exists.

When using the term 'paradigmatic approach' in relation to Indigenous methodologies, this means that this particular research approach flows from an Indigenous belief system that has at its core a relational understanding and accountability to the world (Steinhauer, 2001; Wilson, 2001). Indigenous epistemologies hold a non-human centric relational philosophy (Deloria, 2004; Ermine, 1995) and while tribal groups hold differing relationships with place, as evident in local protocol and custom, (Battiste \& McConaghy, 2005) there is a shared belief system among tribal groups (Littlebear, 2000). This distinctive Indigenous paradigmatic orientation is a theory of how knowledge is constructed and as such it guides assumptions about what counts as knowledge (Kirby et al., 2006) and offers guidance for research methods. Such methods include sharing knowledge based in oral history and storytelling tradition (Hart, 2002; Henderson, 2000; Smith, 1999) and is collectivist (Deloria, 2004). It assumes that knowledge is transferred through oral history and story (Archibald, 2008) and that knowledge is co-created within the relational dynamic of self-in-relation (Graveline, 1998). The relational dynamic between self, others, and nature is central.

An Indigenous paradigm welcomes a decolonizing perspective. One could (and ought to) argue that a decolonizing theoretical perspective is necessary within Indigenous research given the existing social inequities that Indigenous peoples continue to experience. A decolonizing perspective is significant to Indigenous research because it focuses on Indigenous-settler relationships and seeks to interrogate the powerful social relationships that marginalize Indigenous peoples (Nicoll, 2004). Interrogating the power relationships found within the Indigenous-settler dynamic enables a form of praxis that seeks out Indigenous voice and representation with research that has historically marginalized and silenced Indigenous peoples (Smith, 1999). However, paradigmatically speaking, a decolonizing perspective and Indigenous epistemologies emerge from different paradigms. Decolonizing analysis is born of critical theory found within the transformative paradigm of western tradition (Mertens, 2005). It centres the settler discourse, whereas an Indigenous paradigm centres Indigenous knowledges. While a decolonizing perspective remains necessary and can be included as a theoretical positioning within research, it is not the epistemological centre of an Indigenous methodological approach to research.

An understanding of the relational nuances of an Indigenous paradigm is critical to moving forward with an Indigenous methodological approach. Further, it is central in understanding why the conversational method, which is inherently relational, is congruent with Indigenous methodologies.

\section{The Conversational Method}

The conversational method aligns with an Indigenous worldview that honours orality as means of transmitting knowledge and upholds the relational which is necessary to maintain a collectivist tradition. Story is a relational process that is accompanied by particular protocol consistent with tribal knowledge identified as guiding the research (Thompson, 2008, Kovach, 2009). Indigenous scholars within and outside the Canadian context have referenced the use of story, through conversation, as a culturally organic means to gather knowledge within research (Thomas, 2005; Bishop, 1999). 
Reflecting upon story as method within research, Wilson (2001) suggests that story is congruent with the relational dynamic of an Indigenous paradigm. He goes on to say that when you consider the relationship that evolves between sharing story and listening, "it becomes a strong relationship." (p. 178). Thomas (2005) utilized a storytelling methodology in her graduate research on the experiences of individuals who attended Kuper Island Residential School. In reflecting why she chose stories as a method for her research, she reminisces on the stories her grandmothers passed along to her, how these stories shaped Thomas's core being, and that such stories were "cultural, traditional, educational, spiritual, and political" (p. 240). Thomas goes on to state that storytelling has a holistic nature that provides a means for sharing remembrances that evoke the spiritual, emotional, physical, and mental. In reflecting upon story as a dialogic method that evokes the relational, Maori researcher Russell Bishop (1999) introduces the notion of "collaborative storying" (p. 6) which positions the researcher as a participant. As both parties become engaged in a collaborative process, the relationship builds and deepens as stories are shared.

In a presentation at the Fourth International Congress of Qualitative Inquiry, University of Illinois, Bessarab (2008) presented on yarning as method. In her presentation she shares that yarning is a Noongar term for having a conversation or talk. She goes on to say that that there are different forms of yarning which includes social yarning, research yarning, collaborative yarning, and therapeutic yarning. She identifies research yarning as that which is directed around a particular area of curiosity with a specific purpose in mind. From a Native Hawaiian perspective, Kahakalua (2004) comments on the flexibility inherent within a conversational method that aligns with the Native Hawaiian epistemology. "Many of the these conversations were informal, conversational interviews - what Hawaiians call talk story" (p. 24). Certainly, the conversational method is not unique to Indigenous methodologies. It can be found within narrative inquiry, as Barrett \& Stauffer (2009) state narrative is viewed as story and is seen as a "mode of knowing" that is involved in knowledge construction, and has recently been accepted as a "method or inquiry" (p. 7). The conversational method is found within western qualitative research. However when used in an Indigenous framework, a conversational method invokes several distinctive characteristics: a) it is linked to a particular tribal epistemology (or knowledge) and situated within an Indigenous paradigm; b) it is relational; c) it is purposeful (most often involving a decolonizing aim); d) it involves particular protocol as determined by the epistemology and/or place; e) it involves an informality and flexibility; f) it is collaborative and dialogic; and $\mathrm{g}$ ) it is reflexive. The following two research projects illustrate how these characteristics work in tandem with a conversational method to form an Indigenous approach to research.

\section{Two Research Projects Using the Conversational Method}

The remainder of this article focuses on two qualitative research projects that I conducted using a conversational method for gathering data and are situated within an Indigenous research framework. The first study presented (Project One) was completed in 2006; the second study (Project Two) is currently in the data analysis phase. After presenting the studies, I will offer a reflection on implications arising from using this particular method.

Project One: Searching for Arrowheads: An Inquiry into Approaches to Indigenous Research Using Plains Cree Ways of Knowing

Purpose: The project was completed in 2006. This research explored the challenges facing Indigenous doctoral researchers of engaging Indigenous knowledges in their research methodology. This study explored whether this group was applying cultural knowledge into their research methodology and if they felt that there was a distinctive methodological approach that could be described as Indigenous. This study sought further clarity into the characteristics of Indigenous methodologies including choice of method congruent with an Indigenous paradigm.

Research Question: To prompt conversation on this topic there were three main research questions posed: a) How do Indigenous researchers understand cultural aspects of Indigenous research; b) How do Indigenous researchers incorporate cultural knowledges into their research methodology; and c) What are the challenges that Indigenous researchers face in integrating Indigenous ways of knowing within western research methodologies.

Sampling and Participants: Criterion sampling was used. Criteria included Indigenous individuals who have carried out research at a doctoral level within Education and Social Work, representation of participants who conducted human subject research for their doctoral studies, and representation of participants who had recent graduate school experience. The participants in the sample included three in-progress $\mathrm{PhD}$ candidates, one participant just prior to defense, and two participants who completed. Four participants were of Cree ancestry, one was Anishnaabe, and one was Maori. Three participants were in the field of Education and three were in the field of Social Work. Three were men and three were women. With this sample all participants were given the choice to waive confidentiality and all did. 
Methodology: The methodology for this study was a mixed qualitative approach that utilized an Indigenous methodology based upon Plains Cree epistemology for gathering knowledge and interpretation, and a nonIndigenous approach of thematic analysis for organizing data. It incorporated a decolonizing theoretical lens. A conversational method, congruent with Plains Cree epistemology, was utilized. The conversational method employed is best described as dialogic approach to gathering knowledge that is built upon an Indigenous relational tradition. It utilized open-ended, semistructured interview questions to prompt conversation where participant and researcher co-create knowledge. It was the symbiotic relationship between the Indigenous epistemology, method, and interpretation that qualifies it as an Indigenous methodology (Kovach, 2009). Congruent with Plains Cree tribal epistemology, relational accountability, and respect for local protocol, this method involved a small gift and tobacco to show acknowledgement of the relationship and respect for the insights being offered. This signified a commitment by the researcher that the research will be used purposefully (Kovach, 2009).

Findings: Findings were presented in two forms. First, the findings were presented as condensed stories which provided context and voice of the participants. To make meaning, each condensed story was followed by a reflective narrative by the researcher indicating key teachings received from the conversations and stories. Secondly, through a qualitative coding process, the findings were thematically analyzed. Though different processes were employed, the reflective narrative and the thematic grouping emerged with similar findings. The study found that an Indigenous methodology includes evidence of a tribal epistemology, integration of a decolonizing aim, acknowledgement of preparations necessary for research, space for self-location, a clear understanding of purposefulness and motivation of the research, guardianship of sacred knowledges, adherence to tribal ethics and protocol, use of Indigenous methods (as conversation and story), and giving back (Kovach, 2006).

\section{Project Two: Pilot study of support required by non} Indigenous faculty to integrate and enhance Indigenous knowledges within course content at the College of Education, University of Saskatchewan.

Purpose: This project is currently active. Recent provincial curricular reform in Saskatchewan is moving toward the integration of an Indigenous perspective throughout K-12 and has recently integrated mandatory Treaty education throughout the K-12 curriculum (Saskatchewan Ministry of Education, 2009). In part, this move is a means to improve high school completion rates among Indigenous students, a concern that has been documented in the literature (Wotherspoon, 2006; Kanu, 2005). Research shows that a pedagogical approach toward integrating Indigenous perspectives that is beneficial to Indigenous students in the K-12 school system requires an anti-racist, decolonizing knowledge of Indigenous worldviews, community, and cultural norms (St. Denis \& Schick, 2005; Weenie, 2008). Given the move toward mandatory integration of Indigenous perspectives, as in Saskatchewan, it is anticipated that post-secondary teacher education programs will have the responsibility of preparing teacher candidates to competently integrate Indigenous perspectives into their teaching practice. Through their instructional choices and actions, teacher educators powerfully influence the extent to which teacher candidates teaching practices uphold Indigenous culture and work to decolonize. Adequately preparing teacher candidates to confidently integrate Indigenous perspectives in their teaching is dependent upon the Indigenous academic community and the involvement of the non-Indigenous faculty. This cannot be done solely by Indigenous post-secondary education faculty, nor should this group own the full responsibility of this task. Without the involvement of non Indigenous faculty, many of whom teach core courses in pre-service teacher training programs, movement forward will be stymied.

Research Question: This research question asked non Indigenous faculty within the College of Education, University of Saskatchewan the following questions: a) how did they understand Indigenous knowledges and support of Indigenous knowledges; b) how did they see themselves as being a facilitator and/or support to Indigenous students and non Indigenous students who wish to explore Indigenous knowledges in course work; c) what supports, materials, and resources did they find useful, as faculty, in nourishing Indigenous knowledges in their classrooms; d) what did they require from Indigenous faculty, non Indigenous faculty, and administration; and e) what did they see as personal and systemic challenges to integrating Indigenous knowledges into course content.

Sampling and Participants: Criterion sampling was used. Participants were selected with the goal of seeking a participant sample from the College of Education, University of Saskatchewan with representation from faculty who currently instruct undergraduate and/or graduate courses. Because the study was asking for specific insight into non Indigenous faculty experience, this particular group was the focus. Prospective participants were recruited through a letter of invitation from the researcher inviting participation in the research. The letter of invitation was circulated by email to faculty members through a College listserve. In the research design, the goal was to have four to six participants in the study. However, the response 
was double and in the spirit of inclusivity all participants who wished to participate were involved. Eleven faculty participated in the study.

Methodology: As with Project One, this research design is based upon a mixed qualitative method approach including Indigenous methodology (Wilson, 2001), born of place, based on a Plains Cree Worldview (Kovach, 2009) for gathering and interpreting data, and grounded theory for data organization. As with Project One a conversational method congruent with an Indigenous paradigm was used. This project incorporated a bi-cultural theoretical perspective for interpreting and making meaning of the participant stories. This included a decolonizing theoretical lens to analyze the power dynamic inherent in the research curiosity. In conjunction, an Indigenous relational theoretical approach was used to offer a relational analysis given that the research curiosity has as a focus western culture's relational intersection with Indigeneity.

Preliminary Findings: This project is at the data analysis phase with preliminary findings suggesting several intersecting relational aspects (self, colleagues, content, students, institution, and community) influencing the integration and enhancement of Indigenous knowledges into core curriculum. The goal of this research is to provide insight on this research question from this group, then to develop recommendations of how to support non Indigenous faculty in enhancing and integrating Indigenous knowledges in core curriculum in a way that works to decolonize.

In reflecting upon the use of the conversational method within an Indigenous methodological approach for the above research projects, it is helpful to identify several similarities and differences between the two projects. Indentifying the similarities of each is useful in illustrating how a conversational method used within an Indigenous paradigm can adapt to the beliefs and values of that particular paradigm. By articulating the differences of the conversational method in two unique contexts, one can see the flexibility of this method in accommodating the particulars of given research projects.

A consistent similarity in both projects was the rationale of using a conversational method because it served a belief about knowledge as a "self-in-relation" (Graveline, 2000, p.361) process. This included an Indigenous holistic sensibility about what "self-in-relation" means. Using a conversational method within a focus group, Lavellee (2009) offers an interpretation of a holistic approach. "In a research setting, although both the focus group and the sharing circle are concerned with gaining knowledge through discussion, the principles behind a sharing circle are quite different. Circles are acts of sharing all aspects of the individual...' (p. 29). In preparing for both interviews and inviting participants, all participants were from a larger Indigenous academic community to which I belonged. I had either met or had already known the individuals that I interviewed, and would continue to have collegial relationships with the participants engendering a clear sense of "relational accountability" (Wilson, 2008, p.97). Dialogue was an effective method to co-create knowledge in a relational context of a conversation. Engaging in conversation with individuals who knew me and whom I knew created a certain level of trust and reciprocity within the dialogue. The majority of participants had a sense of me as researcher including my perspective on colonialism and its impact on Indigenous peoples. While there were semi-structured questions developed to guide and prompt questions, there was flexibility for both the participant and researcher to participate in the form of a dialogue. It was, as Bessarab (2008) states, a form of yarning. In both projects, there was room for the research participant to tell their story on their own terms (Thomas, 2005). Interspersed as researcher, I also shared my story. At times this meant that the conversation veered away from the prompt questions. In both instances participants had opportunities to approve transcripts and remove or revise any information they did not feel comfortable including in the transcript. Because the methodologies in both projects were grounded in Plains Cree knowledge, the protocol of gifting was in place to acknowledge the teachings that were shared. It also signified a relationship of responsibility on part of both the researcher and participant. Other similarities also existed in both projects. Both groups of participants in the two different projects were part of the academic community and both groups of participants chose the sites and times for interviews. In each context, the conversational method, congruent with an Indigenous paradigm, honoured core Indigenous research values of respect, relevancy, reciprocity, and responsibility.

While the two projects shared similarities there were a couple of contrasts that are worth mentioning as they impacted decisions about analysis. For Project One, the research participants were all Indigenous, whereas in Project Two all of the participants were non-Indigenous. While both groups belonged to the academic community, the participants in Project One were members of the larger Indigenous academic community with only two of six participants employed by the same university at the time of the interview. In Project Two all of the participants were faculty members of the same College of Education in one university. In Project One participants were given the option of waiving confidentiality, of which all did. In Project Two, confidentiality has been maintained. In Project One the research participant stories were presented in two ways. The first was through providing a condensed presentation of the participant's story followed by reflective analysis by the researcher. This provided for a more Indigenous 
contextual presentation of knowledge. Given that the research was inquiring into the nature of Indigenous knowledge, and given that Indigenous knowledge is "personal and particular" (Battiste \& Henderson, 2000, p. 36), a contextual presentation of findings was appropriate. Secondly, the knowledge gathered in the project was thematically grouped. This allowed for a succinct (though non-contextual) analysis of findings. In Project Two the knowledge gathered through the conversational method was solely thematically grouped using grounded theory. A reason for using grounded theory was to build theory on infusing Indigenous knowledges into western core academic curriculum. A further reason for this approach was to aggregate the data as a means of ensuring all identifying information was removed.

In considering the similarities and differences of each project using the same data gathering method, I would like to reflect on some insights I gained along the way. This is presented in less of an academic analysis and more along the lines of 'signposts on the research journey' as it relates to employing a conversational method congruent with an Indigenous paradigm.

The use of a conversational method within an Indigenous research framework has several implications for the researcherin-relation. For the conversational method, the relational factor - that I knew participants and they knew me - was significant. In each case I had known or met participants prior to the research. With this method the researcher must have a certain amount of credibility and trustworthiness for people to participate in the research. With more trust there is the likelihood of deeper conversations, and consequently the potential for richer insights to the research question. The conversations were dialogic, relational, and reflective. As a result I found that I had to work to be an active listener. As an active listener and participant in the research, the process felt less extractive and one-sided (even with the given that research can inevitably be an extractive process). Because I was a co-participant, my own self-knowledge deepened with each conversation. After the conversations, in reading through the transcripts and post-conversation notes, I was able to identify areas that were of concern to me which I was not fully cognizant of prior to the research. The conversation itself helped to deepen relationships with the research participants who also comprised my collegial community. In all cases, participants shared stories from their lives resulting in a highly contextualized, powerful source of knowledge. In receiving the gift of story, I was ever mindful of the responsibility inherent in research and the reciprocity it entails.

In reflecting upon the conversational method, there is a direct inter-relationship between this form of method, ethics, and care. With respect to research conducted in an Indigenous community, there are specific ethical guidelines that include, but are not limited to, a mutually respectful research relationship; that the research benefit the community; that appropriate permission and informed consent is sought; that the research is non-exploitive and non-extractive; and that there is respect for community ethics and protocol. As a means to ensure ethical conduct in research involving Indigenous communities there have been several guideline documents developed. Such guidelines include the Canadian Institute of Health Research (CIHR) Guideline for Health Research Involving Aboriginal Peoples (Canadian Institute of Health Research, 2007); Ownership, Control, Access, and Possession (OCAP) Principles of applied to research in Aboriginal communities (Schnarch, 2004); and the Tri-Council Policy Statement Revised Draft Statement (Chapter 9) (Tri-Council Policy Statement, 2009). These provisions offer guidelines to ensure respect, reciprocity and transparency for all aspects of a research project. Method is one aspect of the research that carries with it its own ethical considerations.

In reflecting on the conversation as method, Haig Brown (1995) makes this important point: "Perhaps because it only rarely that people have the full attention of another adult human being, the interviews often became very intimate ... This sense of intimacy may lead the study participant to take some risks" (p. 30). In concluding this article, I offer several reflections on the ethics of using a conversational method in research. Some may apply to some research contexts and not others, but I believe they are important considerations particularly for research in areas as social work, health and education. Preparation for the research is important when using the conversational method. Within Indigenous methodologies preparation may take many forms including western traditional preparation of research that includes review of literature, decisions about design and so forth; however, within Indigenous methodologies preparation also included interpersonal, relational preparation (i.e. participation in ceremony, visiting community). In using a conversational method, that is inherently relational, the preparation is critical to preparing the researcher and prospective participants. Reciprocity, so integral to Indigenous methodologies, begins at the preparation phase (not completion) and it is here where there can be discussions of how the research (and researcher) will give back to the community.

Preparation is particularly important when the research involves sensitive inquiries as child abuse or family violence studies. Individuals may become emotionally triggered. If it is indeed a sensitive topic, the researcher needs to be aware of the supports in the community and how to support research 
participants if the need arise. In both research projects that I carried out, the topic did not illicit strong deep-seated emotional responses, but this method (particularly if there is a level of trust) has the potential to evoke strong emotions. In situations where the topic is sensitive, a pre-research discussion could help to prepare research participants, it is also a good opportunity to review consent forms. If emotions do arise in the research, the researcher needs to be prepared to respond accordingly. This may mean turning off the audio-tape, sitting with the participant, and being knowledgeable of support services in the community to suggest to the participant. Again depending upon the research context, it is important to be knowledgeable about professional codes around disclosure of child abuse and neglect, and to inform participants if it might be an issue.

In addition to supporting others, it is important to bear in mind that as the researcher you may be triggered. Self-care is important which means taking the time needed between interviews and having one's own support system in place. Research with Indigenous peoples is holistic for both researcher and participant: one respects self and others by being prepared. This was important for me in both research projects (cited above). Because each project dealt with colonialism, I often had to have quiet time by myself between interviews to process the feelings that emerged for me as a result of the discussion. The conversational method evokes stories, our own and others. As Lynne Davis states (2004), "Stories cement together generations of collective memory, embodying the historical, spiritual, social, and spatial" (p. 3) Stories have the power to holistically engage. Allowing time to process stories is a way of respecting self and others. It is respectful and ethical. It was important to have general support systems in place while conducting research, this is a part of preparation and care.

Prior to concluding this article, I would like to add a brief note about analysis. The conversational method (whether it be in one-to-one discussions or research circles) has the means to generate highly contextualized stories. In using a conversational method that is guided by an Indigenous paradigmatic approach, I struggle in decontextualizing and fragmenting the data. However, in situations where confidentiality is not waived, it can be difficult to present highly contextual data while maintaining confidentiality. Further, to thematically group stories works to fragment data. In this process the researcher maintains the power in determining the analysis whereas in presenting a story as data the research participant's story is intact and speaks for itself. Within Indigenous methodologies, the organization of data for purposes of analysis requires ongoing conversation.
In concluding this article, my final thought references back to the inter-relationship between paradigm and method. If the conversational method is to serve an Indigenous methodology (or Indigenous research framework), that has at its core an Indigenous paradigm, then the researcher needs to consistently reflect back upon the inter-relationship between the philosophical values of an Indigenous paradigm and the method being used. So long as both paradigm and method are front and centre (and congruent), the researcher will be effective in serving the research and the research community which includes Indigenous peoples.

\section{References}

Absolon, A., \& Willett, C. (2004). Aboriginal research: Berry picking and hunting in the $21^{\text {st }}$ century. First Peoples Child \& Family Review, $1(10), 5-17$.

Archibald, J. (2008). Indigenous storywork: Educating the heart, mind, body, and spirit. Vancouver: UBC Press.

Atleo, E. R. (2004). Tsawalk: a Nuu-chah-nulth worldview. Vancouver: UBC Press.

Barrett, M., \& Stauffer, S. (2009). Narrative Inquiry: From Story to Method. In M. Barrett \& S. Stauffer (Eds.), Narrative Inquiry into Music ( pp. 7-17). Netherlands: Springer.

Battiste, M., \& Henderson, J. Y. (2000). Protecting indigenous knowledge and heritage: a global challenge. Saskatoon: Purich.

Battiste, M., \& McConaghy, C. (2005). Introduction: Thinking places: Indigenous humanities and education. Australian Journal of Indigenous Education, 34, 156-161.

Bessarab, D. (2008). Yarning about different types of yarning in the doing of Indigenous research. Fourth International Congress of Qualitative Inquiry, Illinois, USA, May 14-17. Retrieved from http://74.125.95.132/search?q=cache:_QvyYXTQwyIJ:cih.curtin. edu.au/local/documents/researchSymposia/Doctoralforum DBessarab.pps+Indigenous + yarning + Dawn\&cd $=1 \& \mathrm{hl}=\mathrm{en} \& \mathrm{ct}=\mathrm{clnk} \&$ $\mathrm{gl}=\mathrm{ca}$.

Bishop, R. (1999). Collaborative storytelling: Meeting Indigenous people’s desires for self-determination. Paper presented at the World Indigenous People's conference, Albuquerque, New Mexico, June 15-22.

Canadian Institutes of Health Research, (2007). CIHR Guidelines for Health Research Involving Aboriginal People. Retrieved from: http:// www.cihr-irsc.gc.ca/e/29134.htm.

Castellano, M. B., Davis, L., \& Lahache, L. (2000). Aboriginal education: Fulfilling the promise. Vancouver: University of British Columbia.

Creswell, J.W. (2003). Research design. Qualitative, quantitative and mixed methods approaches. Thousand Oaks, CA: Sage.

Davis, L. (2004). Risky stories: Speaking and writing in colonial spaces. Native Studies Review, 15(1), 1-20.

Deloria Jr., V. (2004). Philosophy and the Tribal Peoples. In Anne Waters (Ed). American Indian Thought: Philosophical Essays ( pp. 3-11). Malden MA: Blackwell Publishing 


\section{Conversational Method in Indigenous Research}

Denzin, N. \& Lincoln, S. (Eds). (2003). The landscape of qualitative research: Theories and issues. Thousand Oaks, CA: Sage Publications.

Ermine, W. (1995). Aboriginal epistemology. In Battiste (Ed.), First Nations education in Canada: The circle unfolds, (pp. 101-112). Vancouver: UBC Press.

Graveline, F.J. (2000). Circle as methodology: Enacting an Aboriginal paradigm. Qualitative Studies in Education, 13(4), 361-370.

Graveline, F. (1998). Circle works: Transforming Eurocentric consciousness. Nova Scotia: Fernwood Publishing.

Haig-Brown, C. (1995). Power and Contradiction in First Nations Adult Education. Vancouver: UBC Press.

Hart, M.A. (2002). Seeking Mino-Pimatisiwin: An Aboriginal approach to healing. Halifax, NS: Fernwood Publishing.

Henderson, J.Y. (2000). Ayukpachi: Empowering Aboriginal thought. In M. Battiste (Ed.), Reclaiming indigenous voice and vision (pp. 248-278). Vancouver, BC: University of British Columbia Press.

Kahakalau, K. (2004). Indigenous heuristic action research: Bridging western and Indigenous research methodologies. Hulili: Multidisciplinary research on Hawaiian well-being, 1(1), 19-33.

Kanu, Y. (2005). Teachers' Perceptions of the Integration of Aboriginal Culture into the High School Curriculum. Alberta Journal of Educational Research, 51(1), 50-68.

Kirby, S., Greaves, L., \& Reid, C. (2006). Experience Research Social Change - Methods beyond the mainstream. Peterborough: Broadview Press.

Kovach, M. (2005). Emerging from the margins: Indigenous methodologies. In L. Brown \& S. Strega (Eds.), Research as resistance, critical, indigenous and anti-oppressive approaches (pp. 19-36). Toronto: Canadian Scholars' Press.

Kovach, M. (2006). Searching for arrowheads: An Inquiry into approaches to Indigenous research using a tribal methodology with a Nêhiýaw Kiskêyihtamowin worldview. Unpublished doctoral dissertation, University of Victoria, Canada.

Kovach, M. (2009). Indigenous Methodologies: Characteristics, Conversations, and Contexts. Toronto: University of Toronto Press.

Lavellee, L. (2009). Practical application of an Indigenous research framework and two qualitative Indigenous research methods: Sharing circles and Anishnaabe symbol-based reflection. International Institute for Qualitative Methodology. 8(10). Retrieved from http:// creativecommons.org/licenses/by/2.0.

Little Bear, L. (2000). Jagged worldviews colliding. In M. Battiste (Ed.), Reclaiming indigenous voice and vision (pp.77-86). Vancouver, BC: University of British Columbia Press.

Mertens, D.M. (2005). Research and evaluation in education and psychology: integrating diversity with quantitative, qualitative, and mixed methods (2nd ed.). Thousand Oaks, California: Sage Publications.

Meyer, Manu A. (2001). Our own liberation: Reflections on Hawaiian epistemology. The Contemporary Pacific, 13(1): 124-148.

Meyer, M. A. (2001). Acultural Assumptions of empiricism: A Native Hawaiian critique. Canadian Journal of Native Education, 25 (2), 188-198.
Neuman, W. L. (6th ed.). (2006). Social research methods-Qualitative and quantitative approaches. Boston: Pearson Education.

Nicoll, F. (2004). "Are you calling me a racist?": Teaching critical whiteness theory in Indigenous sovereignty. Borderlands 3(2). Retrieved from http://www.borderlands.net.au/vol3no2_2004/nicoll teaching.htm.

Saskatchewan Ministry of Education (2009). Inspiring Success Building Towards Student Achievement. Retrieved from http://www.education. gov.sk.ca/inspiring-success.

Schnarch, B. (2004). Ownership, control, access, and possession (OCAP) or self-determination applied to research: a critical analysis of contemporary First Nations research and some options for First Nations communities. Journal of Aboriginal Health, 1(1), 80-94.

Smith, L. T. (1999). Decolonizing Methodologies: Research and Indigenous peoples. London: Zed Books.

St. Denis, V., \& Schick, C. (2005). Troubling Discourses in Anti-Racist Curricular Planning. Canadian Journal of Education, 28(3), 295-317.

Steinhauer, P. (2001). Situating Myself in Research. Canadian Journal of Native Education, 25(2), 183-187.

Stewart, S. (2009) One Indigenous academic's evolution: A personal narrative of Native health research and competing ways of knowing. First Peoples Child \& Family Review, 4(1), 57-65.

Strega, S. (2005). The View from the Poststructural Margins: Epistemology and Methodology Reconsidered. In Brown \& Strega (eds). Research as Resistance - Critical, Indigenous and anti-oppressive approaches (pp. 199-254). Toronto: Canadian Scholars Press.

Thomas, R (2005) Honouring the oral traditions of my ancestors through storytelling. In Brown \& Strega (eds). Research as Resistance Critical, Indigenous and anti-oppressive approaches (pp. 237-254). Toronto: Canadian Scholars Press.

Thompson, J. (2008). Hede kehe'hotzi'kahidi': My Journey to a Tahlatan Research Paradigm. Canadian Journal of Native Education, 31 (1) 24-39.

Tri-Council Policy Statement Revised Draft $2^{\text {nd }}$ Edition (2009). Retrieved from http://pre.ethics.gc.ca/eng/policy-politique/initiatives/ revised-revisee/Default/.

Weenie, A. (2008). Curricular Theorizing from the Periphery. Curriculum Inquiry, 38(5), 545-557.

Wilson, S. (2001). What is Indigenous research methodology? Canadian Journal of Native Education, 25 (2), 175-179.

Wilson, S. (2008). Research is Ceremony - Indigenous Research Methods. Nova Scotia: Fernwood Press.

Wotherspoon, T. (2006). Teachers' work in Aboriginal communities. Comparative and International Education Society, 50 (4), 672-694. 